\title{
A Highly Selective and Sensitive Thorium(IV) PVC Membrane Electrode Based on a Dithio-tetraaza Macrocyclic Compound
}

\author{
Sulekh Chandra, ${ }^{\dagger}$ Himanshu Agarwal, and Chandan Kumar Singh \\ Department of Chemistry, Zakir Husain College (University of Delhi), \\ J.L. Nehru Marg, New Delhi-110 002, India
}

\begin{abstract}
A poly(vinyl chloride)-based membrane composed of dithio-tetraaza macrocyclic compound as a neutral carrier with sodium tetraphenylborate (NaTPB) as an anion excluder and nitrobenzene (NB) as plasticizer was prepared and investigated as a Th(IV)-selective electrode. The electrode exhibits a Nernstian slope of $14.2 \pm 0.3 \mathrm{mV}$ per decade over a wide concentration range $\left(1.0 \times 10^{-6}\right.$ to $\left.1.0 \times 10^{-1} \mathrm{M}\right)$ with a detection limit of $8.0 \times 10^{-7} \mathrm{M}$ between $\mathrm{pH} 3.5$ and 9.5. The response time of the sensor is about $10 \mathrm{~s}$ and it can be used over a period of 5 months without any divergence in potential. The proposed membrane sensor revealed a good selectivity for Th(IV) over a wide variety of other metal ions and proved to be a better electrode in many respects than those reported in the literature. It was successfully applied as an electrode indicator as well as in the direct determination of thorium ions in standard and real samples.
\end{abstract}

(Received August 9, 2006; Accepted November 24, 2006; Published April 10, 2007)

\section{Introduction}

Thorium is surprisingly abundant in the Earth's crust, being almost as abundant as lead and three times more abundant than uranium. It is found in small amounts in most rocks and soils. Granitile contains up to $80 \mathrm{ppm}$ of thorium. Thorium occurs naturally as the minerals thorite, uranothorite, and thorianite. It is a major component of monazite and it is present in significant amounts in the minerals zircon, titanite, gadolinite and betafite. The amounts of thorium in the environment may be incidentally increased due to accidental releases of thorium processing plants. Uncontrolled large amounts of thorium may be found near hazardous waste sites where thorium has not been disposed of according to the proper procedures. People living near these sites may get exposed to more thorium as they breathe in windblown dust and because it ends up in food that is grown near the site. Since thorium has the ability to change genetic arrangements, it may increase the chances of developing the lung diseases and pancreas cancer. ${ }^{1}$ Therefore, more efforts are required to develop ion-selective electrodes of commercial standards for heavy metal ions that are toxic beyond a certain concentration level. ${ }^{2}$

A literature survey showed that only three-potentiometric electrodes are available for detecting and/or measuring and monitoring thorium in environmental media. ${ }^{3-5}$

The present work describes the working of a sensor involving a dithio-tetraaza macrocyclic compound, namely 2,3,7,8tetraphenyl-1,4,6,9-tetraaza-cyclodeca-5,10-dithion-1,3,6,8tetraene (TPTACDTT) as ionophore, $3 \%$ sodium tetraphenyl borate (NaTPB) as an additive and $62 \%$ nitrobenzene (NB) as a plasticizing solvent mediator for thorium(IV) ions. This novel $\mathrm{Th}^{4+}$-selective electrode not only possesses the advantages of the simplicity of the design in membrane preparation but also

$\dagger$ To whom correspondence should be addressed.

E-mail: schandra_00@yahoo.com has a fast response time, good linear range and detection limit and high selectivity over a variety of various metal ions; in many respects the values are better than those reported in the literature. ${ }^{3-5}$

\section{Experimental}

\section{Reagents and chemicals}

Reagent grade benzyl acetate (BA), nitrobenzene (NB), sodium tetraphenyl borate (NaTPB), tetrahydrofuran (THF) and high relative molecular weight PVC (all from Merck and Aldrich) were used as received. The nitrate and chloride salts of all cations used (all from Merck and Aldrich) were of the highest purity available and were used without any further purification except for vacuum drying over $\mathrm{P}_{2} \mathrm{O}_{5}$. Doubly distilled deionized water was used throughout.

\section{Synthesis of ionophore TPTACDTT}

To a hot ethanolic solution $(50 \mathrm{ml})$ of benzil $(0.093 \mathrm{M}, 6.3 \mathrm{~g})$ acidified with $0.5 \mathrm{ml}$ conc. $\mathrm{HCl}$, a hot ethanolic solution $(50 \mathrm{ml})$ of thiourea (0.03 M >2.28 g approx.) was added drop-wise with stirring. Then the reaction mixture was refluxed at $60^{\circ} \mathrm{C}$ for more than $12 \mathrm{~h}$. The reaction mixture was kept in a cool place for $24 \mathrm{~h}$ and finally a light greenish yellow, bright crystalline compound was obtained. This was filtered on a buchner funnel using a suction pump, followed by washing with $\mathrm{EtOH}$ and finally drying in vacuo (Scheme 1). Yield, $40 \%$; $\mathrm{mp}, 286^{\circ} \mathrm{C}$; IR $(\mathrm{KBr})\left(v_{\max } / \mathrm{cm}^{-1}\right), 1450-1300$ (arom. C=N). No prominent peak in regions $3460-3120$ and $1910-1580$ suggests the absence of $\mathrm{C}=\mathrm{O}$ and $-\mathrm{NH}_{2}$ groups. $\mathrm{MS}, \mathrm{m} / \mathrm{z}(\%)$ : the peak at 494 amu $\mathrm{M}^{+}$may be considered for molecular ion $\left[\mathrm{C}_{30} \mathrm{H}_{20} \mathrm{~N}_{4} \mathrm{~S}_{2}\right]^{+}$, which should be at $500 \mathrm{amu} \mathrm{M}^{+}$(as calculated).

\section{Assembly of the electrode}

Construction of the electrode body and the immobilization of crown ether complexes in the PVC matrix membrane were done 


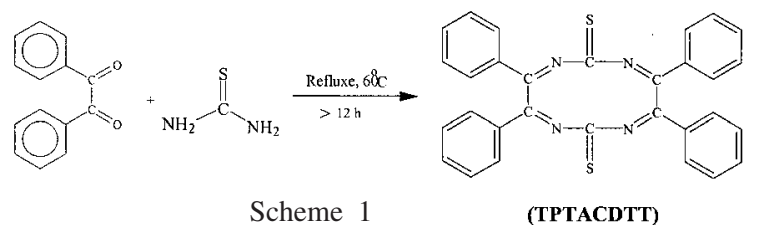

(a)

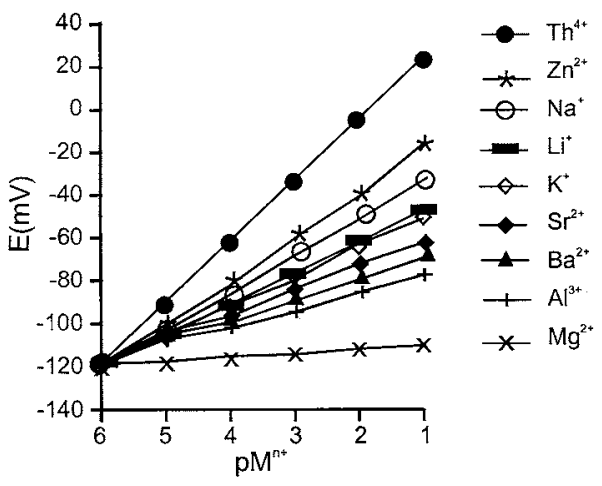

(b)

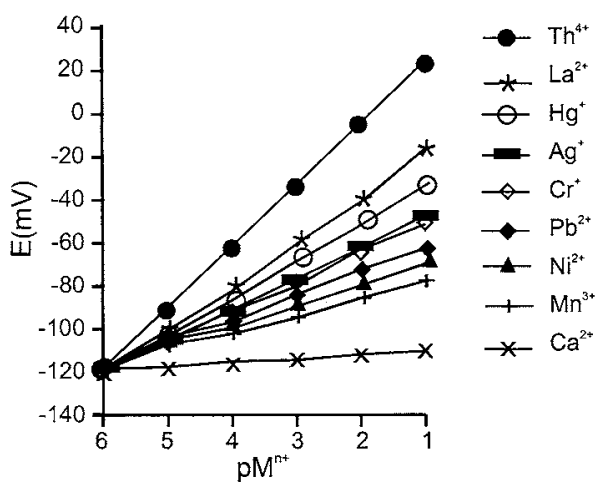

Fig. 1 Potential responses of various ion selective electrodes based on TPTACDTT.

using the method given by Craggs et al. ${ }^{6}$ The glass tube was half filled with $0.01 \mathrm{M} \mathrm{Th}\left(\mathrm{NO}_{3}\right)_{4}$ solution. The membrane was immersed in a standard solution of $0.1 \mathrm{M}$ of the same ion for about $24 \mathrm{~h}$ before using it for measurements.

\section{EMF measurements}

All membrane electrode potential measurements were performed at constant temperature $\left(25 \pm 0.5^{\circ} \mathrm{C}\right)$. The representative electrochemical cell for the EMF measurements are as follows: $\mathrm{Ag}, \mathrm{AgCl} \mid$ int. soln. $\left(0.01 \mathrm{M} \mathrm{AgNO}_{3}\right) \mid \mathrm{PVC}$ membrane | sample $\mid$ salt bridge $\left(1 \mathrm{M} \mathrm{KNO}_{3}\right)|3 \mathrm{M} \mathrm{KCl}|$ $\mathrm{Th}\left(\mathrm{NO}_{3}\right)_{4}$, Th.

The potential readings of the electrodes were measured in stirred solution via a digital $\mathrm{pH}$-meter (Elico LI-10, India). As reference electrode, the saturated calomel was used. The performance of the electrodes was examined by measuring EMFs of the primary ion solutions in the concentration range from $10^{-7}$ to $10^{-1} \mathrm{M}$. A calibration curve was constructed with concentrations ranging from $10^{-7}$ to $10^{-1} \mathrm{M}$. The curves were plotted on Orion 7 cycle-logarithmic graph paper. The selectivity was determined by the mixed solution method. ${ }^{6}$

Determination of thorium(IV) in standard and natural samples Standard rock samples from Indian rare earth metals (India) were analyzed to test the reliability of the present method. The
Table 1 The formation constants of TPTACDTT complexes

\begin{tabular}{cccc}
\hline Cation & $\log K_{\mathrm{f}}$ & Cation & \multicolumn{1}{c}{$\log K_{\mathrm{f}}$} \\
\hline $\mathrm{Th}^{4+}$ & $6.05 \pm 0.01$ & $\mathrm{Ni}^{2+}$ & $2.76 \pm 0.02$ \\
$\mathrm{Fe}^{3+}$ & $3.19 \pm 0.03$ & $\mathrm{Cu}^{2+}$ & $2.20 \pm 0.08$ \\
$\mathrm{Fe}^{2+}$ & $2.25 \pm 0.06$ & $\mathrm{Cd}^{2+}$ & $2.28 \pm 0.09$ \\
$\mathrm{~Pb}^{2+}$ & $3.05 \pm 0.03$ & $\mathrm{Zn}^{2+}$ & $1.17 \pm 0.02$ \\
$\mathrm{Hg}^{2+}$ & $3.32 \pm 0.05$ & $\mathrm{Mg}^{2+}$ & $3.11 \pm 10$ \\
\hline
\end{tabular}

samples were finely crushed, digested in a mixture of perchloric acid and nitric acid, and evaporated to dryness. The residue was redissolved in $0.1 \mathrm{M}$ perchloric acid and diluted to $250 \mathrm{ml}$ with distilled water. An aliquot of the solution was taken for the determination of thorium(IV).

\section{Results and Discussion}

The macrocyclic ionophore TPTACDTT, due to its preoriganizal properties and the presence of heteroatoms (four nitrogen atoms in main ring and two sulfur atoms in side chain) along with aromatic benzene rings, provides a threedimensional framework with high flexibility for complexing the metal ions. Due to its moderately high molecular weight and the soft acidic nature of the ionophore having 10-membered ring, better complexing ability of this ligand with transition metal ions and heavy metal ions is expected. Thus, in order to check the suitability of TPTACDTT as an ion carrier for different metal ions, in preliminary experiments, it was used to prepare PVC membrane ion-selective electrodes for a wide variety of cations, including alkali, alkaline earth transition and heavy metal ions. The potential responses of the most sensitive ion-selective electrodes based on TPTACDTT are shown in Fig. 1.

In order to determine the stability and selectivity of the complexation of TPTACDTT with a number of transition and heavy metal ions, we investigated the complexes conductometrically in acetonitrile solution at $25 \pm 0.1^{\circ} \mathrm{C} .^{8,9}$ The formation constants $\left(\log K_{\mathrm{f}}\right)$ of the resulting 1:1 complexes were determined by computer fitting of the molar conductance-mole ratio data to the appropriate equations. ${ }^{8,9}$ The results are given in Table 1. On the basis of the relative stabilities of the resulting complexes, macrocyclic compound (TPTACDTT) is expected to act as a highly selective ionophore for the thorium ion in the construction of the ion selective electrode. From these conclusions, one can suggest that thorium(IV), which has a coordination number of 8 in solution, may form a 1:2 complex with the ligand (TPTACDTT), using its 4 nitrogen atoms. But there is much possibility of very high kinetics of complex formation and dissociation between Th(IV) ion and the ligand, promoting the proposed membrane sensor as very selective and suitable for $\mathrm{Th}(\mathrm{IV})$ ion.

\section{Potential response of the Th(IV) sensor based on TPTACDTT}

The PVC-based membrane sensor based on TPTACDTT generated stable potential response in aqueous solutions containing thorium ions after conditioning for about $24 \mathrm{~h}$ in a $1.0 \times 10^{-2} \mathrm{M}$ thorium nitrate solution. The potential responses of the Th(IV) PVC-based membrane sensor at varying concentrations of thorium nitrate indicate a linear working concentration range from $1.0 \times 10^{-1}$ to $1.0 \times 10^{-6} \mathrm{M}$. The slope of the calibration graph was $14.2 \pm 0.3 \mathrm{mV}$ per decade of thorium ion concentration. The detection limit of the sensor, determined from the intersection of the two extrapolated 
Table 2 Composition of membrane ingredients

\begin{tabular}{|c|c|c|c|c|c|c|c|}
\hline \multirow{2}{*}{$\begin{array}{c}\text { Membrane } \\
\text { No. }\end{array}$} & \multicolumn{4}{|c|}{ Composition, $\%$} & \multirow{2}{*}{ Slope/mV decade ${ }^{-1}$} & \multirow{2}{*}{ Concentration range/M } & \multirow{2}{*}{ Detection limit/M } \\
\hline & $\mathrm{PVC}$ & TPTACDTT & Plasticizer & Additive & & & \\
\hline 1 & 30 & 22 & 44, DOP & 4, NaTBP & $12.5 \pm 0.4$ & $1.0 \times 10^{-1}-5 \times 10^{-5}$ & $5.5 \times 10^{-5}$ \\
\hline 2 & 30 & 16 & $50, \mathrm{DOP}$ & 4, NaTBP & $13.6 \pm 0.8$ & $1.0 \times 10^{-1}-1.0 \times 10^{-5}$ & $6.5 \times 10^{-4}$ \\
\hline 3 & 30 & 5 & $62, \mathrm{NB}$ & 3, NaTBP & $14.2 \pm 0.3$ & $1.0 \times 10^{-1}-8.0 \times 10^{-6}$ & $8.0 \times 10^{-7}$ \\
\hline 4 & 30 & 8 & $58, \mathrm{AP}$ & 4, NaTBP & $8.0 \pm 0.7$ & $1.0 \times 10^{-1}-5.5 \times 10^{-4}$ & $1.0 \times 10^{-4}$ \\
\hline 5 & 30 & 5 & $65, \mathrm{AP}$ & - & $18.4 \pm 0.6$ & $1.0 \times 10^{-1}-5.5 \times 10^{-5}$ & $5.0 \times 10^{-4}$ \\
\hline
\end{tabular}

Table 3 Selectivity coefficients of various interfering ions

\begin{tabular}{cccc}
\hline Metal ion & \multicolumn{1}{c}{$K_{\mathrm{ij}}$} & Metal ion & \multicolumn{1}{c}{$K_{\mathrm{ij}}$} \\
\hline $\mathrm{Mn}^{2+}$ & $2.7 \times 10^{-6}$ & $\mathrm{Zn}^{2+}$ & $2.1 \times 10^{-4}$ \\
$\mathrm{~K}^{+}$ & $3.7 \times 10^{-5}$ & $\mathrm{Co}^{2+}$ & $3.1 \times 10^{-5}$ \\
$\mathrm{Ni}^{2+}$ & $1.4 \times 10^{-3}$ & $\mathrm{Ba}^{2+}$ & $3.6 \times 10^{-5}$ \\
$\mathrm{Cd}^{2+}$ & $3.9 \times 10^{-3}$ & $\mathrm{Sr}^{2+}$ & $2.5 \times 10^{-5}$ \\
$\mathrm{~Pb}^{2+}$ & $2.6 \times 10^{-4}$ & $\mathrm{Mg}^{2+}$ & $2.7 \times 10^{-3}$ \\
$\mathrm{Hg}^{2+}$ & $3.0 \times 10^{-4}$ & $\mathrm{Ca}^{2+}$ & $3.3 \times 10^{-4}$ \\
$\mathrm{Cu}^{2+}$ & $1.9 \times 10^{-4}$ & $\mathrm{Na}^{+}$ & $1.8 \times 10^{-5}$ \\
\hline
\end{tabular}

segments of the calibration graph, was $8.0 \times 10^{-7} \mathrm{M}$. The standard deviation for 10 replicate measurements was $\pm 0.3 \mathrm{mV}$.

The data obtained with membranes having various ratios of different constituents are listed in Table 2. The potential responses of all the membrane sensors were studied in a wide range of the different concentrations of $\mathrm{Th}\left(\mathrm{NO}_{3}\right)_{4}$ solution. It can be seen from Table 2 that the amount of TPTACDTT up to $5 \%(\mathrm{w} / \mathrm{w})$ resulted in the membranes (Nos. 3 and 5) displaying larger slopes. However, in the presence of an additive NaTBP (3\%), the electrode obtained the Nernstian slope of $14.2 \pm 0.3$ $\mathrm{mV}$ per decade of thorium concentration in the case of membrane No. 3 .

This reason is attributed to the presence of lipophilic anions in cation-selective membrane electrodes such anions diminish the ohmic resistance, enhance the response behavior and selectivity and increase the sensitivity of the membrane electrodes. ${ }^{10-14}$ Thus, the membrane sensor with composition of $30 \%$ PVC; $62 \% \mathrm{NB} ; 3 \% \mathrm{NaTPB}$, and 5\% TPTACDTT exhibits the best performance.

\section{Effect of $p H$ of solution on the response of the sensor}

The $\mathrm{pH}$ dependence of the membrane electrode was evaluated over a pH range of $2.0-10.0$ at the concentration of $1.0 \times 10^{-2}$ $\mathrm{mol} \mathrm{L} \mathrm{L}^{-1}$ of thorium ion concentration; the results are depicted in Fig. 2. As can be seen, the potential remains fairly constant in the $\mathrm{pH}$ range of $3.5-9.5$ (the $\mathrm{pH}$ of the solutions was adjusted by either $\mathrm{HCl}$ or $\mathrm{NaOH}$ solutions). Beyond this range, a gradual change in the potential was detected. The observed potential drift at the higher $\mathrm{pH}$ values may be due to the formation of some hydroxyl complexes of Th(IV) and its insoluble hydroxide; in both cases, such formation reduces the concentration of free $\mathrm{Th}(\mathrm{IV})$ in the solution. At $\mathrm{pH}$ values lower than 3.5, the potentials increase, indicating that the membrane sensor responds to hydrogen ion protonation of nitrogen atoms in the structure of TPTACDTT. The response time $\left(t_{95 \%}\right)$ measured was about $10 \mathrm{~s}$ for $\mathrm{Th}^{4+}$ at $1.0 \times 10^{-2} \mathrm{M}$ concentrations. It is noteworthy that the equilibrium potentials remained essentially constant for more than $5 \mathrm{~min}$, after which only a very small divergence, within the resolution of the $\mathrm{pH}$ meter, was recorded.

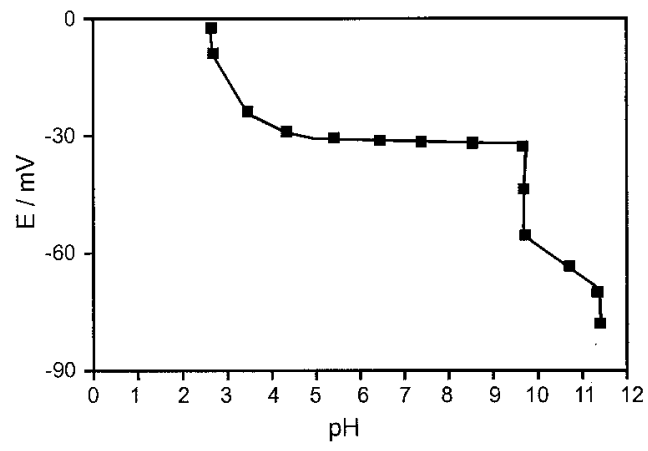

Fig. 2 Effect of $\mathrm{pH}$ on potentiometric response of electrode.

\section{Lifetime of the membrane electrode}

No major variation in any of the response characteristics was observed over a period of 5 months for sensor No. 3. Even so, the sensor was stored in $0.1 \mathrm{M} \mathrm{Th}^{4+}$ solution during non-usage and was re-equilibrated with $1.0 \times 10^{-2} \mathrm{M} \mathrm{Th}^{4+}$ solution whenever any drift in potential was observed. Repeated monitoring of potentials ( 20 measurements) on the same portion of the sample $\left(1.0 \times 10^{-2} \mathrm{M}\right)$ gave a standard deviation of 0.4 $\mathrm{mV}$, while the deviation from the slope was found to be $0.1 \mathrm{mV}$.

\section{Selectivity coefficients}

The effect of interfering ions on the response behavior of the sensors is described in terms of the selectivity coefficients $\left(K_{\mathrm{ij}}\right)$. Methods based on the Nicolsky-Eisenman equation for the determination of potentiometric selectivity coefficients (e.g., the fixed interference method and the mixed solution method) are among the most commonly methods used thus far. ${ }^{15,16}$ However, it has been shown that these methods suffer some limitations in terms of the values for ions of unequal charges, a non-Nernstain behavior of interfering ions and the activity dependence of the value. ${ }^{17,18}$ Thus, in this work, the recommended matched potential method (MPM), which is totally independent of the Nicolsky-Eisenman equation, was used to overcome the above-stated difficulties. ${ }^{19}$ According to the MPM, a specified activity (concentration) of primary ions (A) was added to a reference solution and the potential was measured. In a separate experiment, interfering ions (B) were successively added to an identical reference solution, until the measured potential matched the one obtained before by adding primary ions. The MPM selectivity coefficient $\left(K_{\mathrm{ij}}\right)$ was then given by the resulting primary ion to the interfering ion activity (concentration) ratio, $K_{\mathrm{ij}}=a_{\mathrm{A}} / a_{\mathrm{B}}$. The experimental conditions employed and the resulting values for different $\mathrm{Th}(\mathrm{IV})$ ion sensors are given in Table 3. As can be seen, for all the diverse ions used, the selectivity coefficients in the case of the best composition (No. 3) were of the order of $10^{-3}-10^{-5}$ smaller, indicating that they would not significantly interfere with the 
Table 4 Comparison of the selectivity coefficients $\left(K_{\mathrm{ij}}\right)$, detection limit and response time of various $\mathrm{Th}(\mathrm{IV})$ ion-selective electrode

\begin{tabular}{|c|c|c|c|c|c|}
\hline & \multirow[b]{2}{*}{ Ref. 3 (FIM) } & \multicolumn{2}{|c|}{ Ref. 4 (SSM) } & \multirow[b]{2}{*}{ Ref. 5} & \multirow[b]{2}{*}{ This work (MPM) } \\
\hline & & $\begin{array}{l}\text { Homogenous method } \\
\text { based ionophore }\end{array}$ & $\begin{array}{l}\text { Solid-solid reaction } \\
\text { based ionophore }\end{array}$ & & \\
\hline Detection limit/M & $5 \times 10^{-5}$ & $1.6 \times 10^{-6}$ & $5 \times 10^{-7}$ & $6.0 \times 10^{-6}$ & $8.0 \times 10^{-7}$ \\
\hline Slope/mV decade ${ }^{-1}$ & 50.0 & $15.5 \pm 0.5$ & $16.0 \pm 0.5$ & 14.2 & $14.2 \pm 0.3$ \\
\hline $\mathrm{pH}$ & $3-5$ & $3-5$ & $3-5$ & $2.5-9.0$ & $3.5-9.5$ \\
\hline Response time/s & $5-10$ & 30 & 30 & 15 & 10 \\
\hline$K_{\mathrm{ij}} \quad \mathrm{Ca}^{2+}$ & 1.3 & $8.0 \times 10^{-4}$ & $1.5 \times 10^{-4}$ & $3.1 \times 10^{-4}$ & $3.3 \times 10^{-4}$ \\
\hline $\mathrm{Sr}^{2+}$ & Indeterminate value & Indeterminate value & Indeterminate value & $3.6 \times 10^{-4}$ & $2.5 \times 10^{-5}$ \\
\hline $\mathrm{Ba}^{2+}$ & 1.3 & Indeterminate value & Indeterminate value & $1.4 \times 10^{-4}$ & $3.6 \times 10^{-5}$ \\
\hline $\mathrm{Na}^{+}$ & Indeterminate value & $3.0 \times 10^{-4}$ & $8.0 \times 10^{-4}$ & $3.3 \times 10^{-4}$ & $1.8 \times 10^{-5}$ \\
\hline $\mathrm{K}^{+}$ & Indeterminate value & $2.6 \times 10^{-4}$ & $2.2 \times 10^{-4}$ & $2.3 \times 10^{-4}$ & $3.7 \times 10^{-5}$ \\
\hline
\end{tabular}

Table 5 Analysis of Th(IV) in standard samples and monazite sand

\begin{tabular}{lccc}
\hline \multirow{2}{*}{ Sample No. } & \multicolumn{2}{c}{ Conc. of $\mathrm{Th}^{4+} / \mu \mathrm{g} \mathrm{ml}^{-1}$} & \\
\cline { 2 - 3 } & ISE method & AAS method & \\
\hline Rock sample 1 & $3.22 \pm 0.3$ & $3.37 \pm 0.5$ & 95.5 \\
Rock sample 2 & $2.40 \pm 0.1$ & $2.50 \pm 0.6$ & 96.0 \\
Monazite & $1.47 \pm 0.1$ & $1.50 \pm 0.2$ & 98.0 \\
\hline
\end{tabular}

Average recovery, $96.5 \pm 0.5 \%$.

functioning of the $\mathrm{Th}^{4+}$ ion selective electrode.

Table 4 compares the response time, detection limit and selectivity coefficients of the proposed sensor with the previously reported thorium electrodes. ${ }^{3-5}$ The results clearly indicated the superiority of the proposed electrode in terms of the response time and the selectivity coefficients (for $\mathrm{Ca}^{2+}, \mathrm{Sr}^{2+}$, $\mathrm{Ba}^{2+}, \mathrm{Na}^{+}$and $\mathrm{K}^{+}$ions).

\section{Applications}

The proposed $\mathrm{Th}^{4+}$ ion-selective electrode was found to work well under laboratory conditions. It was successfully applied to the determination of thorium in standard and natural samples. With the use of the membrane sensor's calibration curve, the thorium contents in rock samples and monazite sand samples from triplicate measurements with electrode were found to be in satisfactory agreement with that determined by atomicabsorption spectrometry (Table 5). The total amount of thorium in each of the samples, analyzed by AAS, is considered as its absolute recovery in the sample and the amount of thorium determined by ISE method is considered as relative one and thus the percentage recovery is equal to \{ (relative recovery/ absolute recovery $) \times 100\}$. Averages give average recoveries of the samples analyzed. Besides this, it has also been possible to use the assembly as an indicator electrode in the potentiometric titration of $\mathrm{Th}^{4+}$ with $1 \times 10^{-2} \mathrm{M}$ EDTA, where a sharp inflection point with perfect stoichiometry $\left(\mathrm{Th}^{4+}\right.$ :EDTA $\left.=1: 1.2\right)$ was obtained (Fig. 3). During the titration of of $25.0 \mathrm{ml}$ of Th(IV) $\left(1.0 \times 10^{-2} \mathrm{M}, \mathrm{pH} 3.8\right)$ against EDTA solution $(1.0 \times$ $\left.10^{-2} \mathrm{M}\right)$ taken in the burette, titration curve " $\mathrm{A}$ " represents the decreasing trend of potential response for membrane No. 3 , on addition of lower volume of the titrant to the higher volume of it, and the curve " $\mathrm{B}$ " represents vice versa.

\section{Acknowledgements}

The financial support provided by Defiance Research and

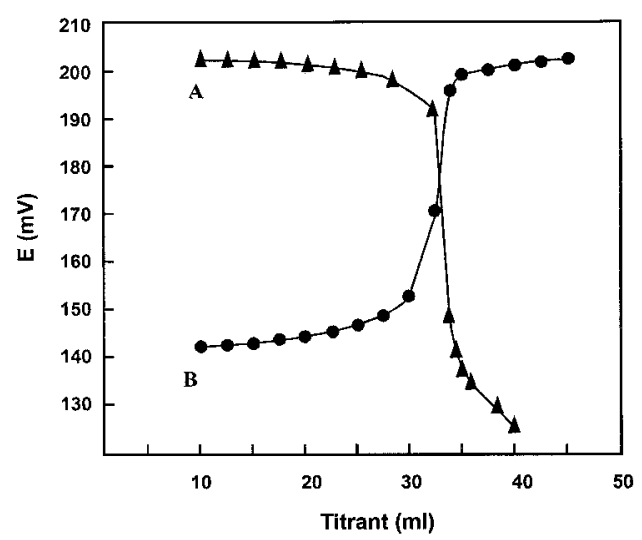

Fig. 3 (A) Titration curve of $25.0 \mathrm{ml}$ of Th(IV) $\left(1.0 \times 10^{-2} \mathrm{M}\right.$, pH 3.8) with EDTA solution $\left(1.0 \times 10^{-2} \mathrm{M}\right)$ and (B) vice versa for membrane No. 3 .

Development Organization (DRDO), New Delhi, India is gratefully acknowledged. One of the authors, C. K. Singh, is thankful to Prof. R. K. Agarwal, L. R. College, Shahibabad, India, for his fruitful suggestions.

\section{References}

1. H. J. M. Bowen, "Environmental Chemistry of the Elements", 1979, Academic Press, London.

2. V. K. Gupta, A. Kumar, and R. Mangla, Sens. Actuators, B, 2001, 76, 617.

3. S. K. Mittal and P. P. Singh, Indian J. Chem., 1995, 34A, 1009.

4. H. A. Arida, M. A. Ahmed, and A. M. El-Saied, Sensors, 2003, 3, 424.

5. S. Chandra, H. Agarwal, C. K. Singh, S. K. Sindhu, and P. Kumar, Indian J. Chem., 2005, 44A, 2060.

6. A. Craggs, G. J. Moody, and J. D. R. Thomas, J. Chem. Educ., 1974, 51, 541.

7. V. K. Jain, S. G. Pillai, R. A. Pandya, Y. K. Agarwal, and P. S. Shrivastava, Anal. Sci., 2005, 21, 129.

8. V. A. Nicely and J. I. Dye, J. Chem. Educ., 1971, 48, 443.

9. M. Shamsipur and M. R. Ganjali, J. Incl. Phenom., 1997, $28,315$.

10. M. R. Ganjali, M. Qomi, A. Daftari, P. Norouzi, and M. Salavati-Niasari, Sens. Actuators, B, 2004, 98, 92.

11. M. R. Ganjali, M. Rahimi, B. Maddah, A. Moghimi, and S. 
Horhani, Anal. Sci., 2004, 20, 1427.

12. M. R. Ganjali, M. Ghorbani, P. Norouzi, A. Daftari, M Faal-Rastegar, and A. Moghimi, Sens. Actuators, B, 2004, 100, 315 .

13. M. R. Ganjali, M. Faal-Rastegar, A. Moghimi, and A. Daftari, Anal. Sci., 2003, 19, 353.

14. E. Bakker, Anal. Chem., 2000, 72, 1127.

15. IUPAC Analytical Chemistry Division, Commission on
Analytical Nomenclature, Pure Appl. Chem., 1976, 48, 127.

16. A. R. Fakhari, M. R. Ganjali, and M. Shamsipur, Anal. Chem., 1997, 69, 3693.

17. T. Ogata, D. A. Chowdhary, S. Kamata, Y. S. Usui, and K. Ohashi, Chem. Lett., 1995, 67, 1041.

18. Y. Umezawa, K. Umezawa, and H. Sato, Pure Appl. Chem., 1995, 67, 507.

19. E. Bakker, Electroanalysis, 1999, 9, 7 